\title{
Combining protein and metabolic engineering strategies for biosynthesis of melatonin in Escherichia coli
}

Yanfeng Zhang ${ }^{1,2+} \mathbb{D}^{0}$, Yongzhi He ${ }^{1 \dagger}$, Nan Zhang ${ }^{1,2}$, JiaJia Gan ${ }^{1,2}$, Shan Zhang ${ }^{3^{*}}$ and Zhiyang Dong ${ }^{1,2^{*}}$

\begin{abstract}
Background: Melatonin has attracted substantial attention because of its excellent prospects for both medical applications and crop improvement. The microbial production of melatonin is a safer and more promising alternative to chemical synthesis approaches. Researchers have failed to produce high yields of melatonin in common heterologous hosts due to either the insolubility or low enzyme activity of proteins encoded by gene clusters related to melatonin biosynthesis.
\end{abstract}

Results: Here, a combinatorial gene pathway for melatonin production was successfully established in Escherichia coli by combining the physostigmine biosynthetic genes from Streptomyces albulus and gene encoding phenylalanine 4-hydroxylase (P4H) from Xanthomonas campestris and caffeic acid 3-O-methyltransferase (COMT) from Oryza sativa. A threefold improvement of melatonin production was achieved by balancing the expression of heterologous proteins and adding 3\% glycerol. Further protein engineering and metabolic engineering were conducted to improve the conversion of $\mathrm{N}$-acetylserotonin (NAS) to melatonin. Construction of COMT variant containing C303F and V321T mutations increased the production of melatonin by fivefold. Moreover, the deletion of speD gene increased the supply of S-adenosylmethionine (SAM), an indispensable cofactor of COMT, which doubled the yield of melatonin. In the final engineered strain ECMEL8, the production of NAS and melatonin reached $879.38 \pm 71.42 \mathrm{mg} / \mathrm{L}$ and $136.17 \pm 1.33 \mathrm{mg} / \mathrm{L}$ in a shake flask. Finally, in a 2-L bioreactor, ECMEL8 produced $1.06 \pm 0.07 \mathrm{~g} / \mathrm{L}$ NAS and $0.65 \pm 0.11 \mathrm{~g} / \mathrm{L}$ melatonin with tryptophan supplementation.

Conclusions: This study established a novel combinatorial pathway for melatonin biosynthesis in E. coli and provided alternative strategies for improvement of melatonin production.

Keywords: Melatonin, N-acetylserotonin, Metabolic engineering, Streptomyces albulus, S-adenosylmethionine

\footnotetext{
*Correspondence: zhangs@outlook.com; dongzy@im.ac.cn

${ }^{\dagger}$ Yanfeng Zhang and Yongzhi He contributed equally to this work

${ }^{1}$ State Key Laboratory of Microbial Resources, Institute of Microbiology,

Chinese Academy of Sciences, No. 1 West Beichen Road, Chaoyang

District, Beijing 100101, People's Republic of China

${ }^{3}$ Shenzhen Siyomicro Bio-Tech C., LTD, No. 39 Qingfeng Avenue, Baolong

Community, Longgang District, Shenzhen 518116, People's Republic

of China

Full list of author information is available at the end of the article
}

(c) The Author(s) 2021. Open Access This article is licensed under a Creative Commons Attribution 4.0 International License, which permits use, sharing, adaptation, distribution and reproduction in any medium or format, as long as you give appropriate credit to the original author(s) and the source, provide a link to the Creative Commons licence, and indicate if changes were made. The images or other third party material in this article are included in the article's Creative Commons licence, unless indicated otherwise in a credit line to the material. If material is not included in the article's Creative Commons licence and your intended use is not permitted by statutory regulation or exceeds the permitted use, you will need to obtain permission directly from the copyright holder. To view a copy of this licence, visit http://creativecommons.org/licenses/by/4.0/. The Creative Commons Public Domain Dedication waiver (http://creativeco mmons.org/publicdomain/zero/1.0/) applies to the data made available in this article, unless otherwise stated in a credit line to the data. 


\section{Background}

Melatonin is an ancient and ubiquitous molecule [1], widely distributed in almost all taxa of living organisms, including microorganisms, plants, and animals [2]. Melatonin is considered one of nature's most versatile biological signals, and its functions have diverged with organismal diversification [3]. Due to its multiple functions [4], melatonin has shown excellent prospects in both medical applications and crop improvement [5-7]. Melatonin has been extensively used as an over-thecounter drug and a dietary supplement for many years word wide. Currently, commercial melatonin relies on chemical synthesis, which is neither sustainable nor environmentally friendly [8-10]. The microbial production of melatonin is a safer and more promising alternative based on the understanding of the melatonin biosynthetic pathway [9].

The biosynthetic pathway of melatonin was first elucidated in animals [11]. In animals, melatonin is synthesized from tryptophan via the 5-hydroxytryptophan (5HTP), serotonin (5HT), and $\mathrm{N}$-acetylserotonin (NAS) intermediates. Accordingly, four enzymes, including tryptophan-5-hydroxylase (TPH), tryptophan decarboxylase (TDC), serotonin $N$-acetyltransferase (SNAT), and $N$-acetylserotonin methyltransferase (ASMT), are involved in the catalytic process [11]. In plants, melatonin biosynthesis also begins with tryptophan and includes four enzymatic steps. However, the process of melatonin biosynthesis in plants differs from that in animals in several aspects [12]. First, the first enzymatic step is tryptophan decarboxylation rather than hydroxylation, as occurs in animals $[13,14]$. Second, the subsequent step is the synthesis of 5-HT, which catalyzed by tryptamine 5-hydroxylase (T5H) [15]. Third, in addition to ASMT, caffeic acid O-methyltransferase (COMT), which is absent in animals, is another enzyme involved in the synthesis of melatonin. It is worth mentioning that COMT has a significantly higher catalytic efficiency than ASMT in the conversion of $\mathrm{N}$-acetylserotonin to melatonin. The catalytic efficiency $\left(V_{\max } / K_{m}\right)$ for COMT activity was 709-fold higher than for ASMT in Arabidopsis thaliana, indicating a pivotal role of COMT in the synthesis of melatonin [16]. Therefore, in plants, a total of six enzymes, namely, TPH, SNAT, ASMT, TDC, T5H, and COMT, are involved in the biosynthetic pathway of melatonin, suggesting the complexity of melatonin biosynthesis [12]. In addition to the classic pathway, an alternate pathway, in which serotonin is first $O$-methylated and the resulting 5-MT is $N$-acetylated, was recently proposed, adding further complexity to the pathway of melatonin biosynthesis $[12,17]$. Compared with the number of studies in animals and plants, there are few studies on the biosynthetic pathway in microorganisms, although melatonin is believed to have first appeared in bacteria as early as billions of years ago [3,17]. The enzymes and corresponding genes involved in melatonin biosynthesis in microorganisms have remained almost unknown.

Therefore, almost all the genes necessary to establish the melatonin biosynthetic pathway in genetically engineered bacteria were cloned from animals and plants [18-20]. Germann et al. [19] established a de novo melatonin biosynthetic pathway in recombinant yeast. In that work, the genes encoding TPH were from either Homo sapiens or Schistosoma mansoni. Moreover, the genes encoding TDC and ASMT were cloned from H. sapiens, and the gene encoding SNAT was cloned from Bos taurus. Recently, Luo et al. established a recombinant melatonin biosynthetic pathway in $E$. coli. The genes encoding $\mathrm{TPH}$ and ASMT were cloned from $H$. sapiens and the genes encoding TDC and SNAT were cloned from Candidatus Koribacter versatilis and Streptomyces griseofuscus respectively [21]. In other attempts to produce melatonin in E. coli, genes encoding SNAT and ASMT were cloned from several animals and plants. When these enzymes derived from mammals and plants are heterologous expressed in E. coli, the expression level is extremely low or the expression product is inactive, which limits the high production of melatonin in prokaryotic cells [20, 22].

To date, the gene cluster involved in melatonin biosynthesis in microorganisms has not been identified. However, a gene cluster responsible for physostigmine biosynthesis in Streptomyces harbors the first three genes that encode enzymes to produce NAS, which is the immediate precursor of melatonin [23]. Physostigmine, a tryptophan-derived heterocyclic alkaloid is first discovered in the seeds of West African beans. As a potent acetylcholine inhibitor, physostigmine is widely used to treat glaucoma and Alzheimer's disease but there are few studies regarding its in-situ function and biosynthesis pathway $[24,25]$. After large scale-up screening, the researchers discovered that submerged cultivation of the actinomycetes Streptomyces griseofuscus and Streptomyces pseudogriseolus can produce physostigmine [25]. In 2014, Liu et al. [23] identified the gene cluster $p s m A$ $H$ responsible for the biosynthesis of physostigmine in Streptomyces griseofuscus. Of these, PsmH and PsmF are required for the NAS biosynthesis starting from 5-HTP, which is shared with the melatonin pathway. Based on the physostigmine biosynthetic pathway, in this paper, a novel biosynthetic pathway for melatonin production was established in $E$. coli. In addition, metabolic engineering and enzyme engineering strategies were employed to optimize the biosynthetic pathway and the production of melatonin was effectively improved by 11 -fold compared to the first generation strain. 


\section{Materials and methods}

\section{Bacterial strains and media}

All bacterial strains used in this study are listed in Table 1. E. coli Trans1-T1 (TransGen, Beijing, China) was used as the host strain for plasmid construction and propagation. E. coli BW25113 tnaA was used for protein expression and in vivo hydroxylation of L-tryptophan to melatonin. For efficient biosynthesis of melatonin, genomic modification of the E. coli BW25113 $\Delta$ tnaA strain was performed using $\lambda$-red recombination [26]. Luria-Bertani (LB) medium containing $10 \mathrm{~g} / \mathrm{L}$ tryptone, $5 \mathrm{~g} / \mathrm{L}$ yeast and $10 \mathrm{~g} / \mathrm{L} \mathrm{NaCl}$ was used for cell cultivation and enzyme expression. Modified M9 medium (M9Y) was used for the in vivo production of 5-HTP and melatonin from L-tryptophan in shake flasks [22]. M9Y medium contained $10 \mathrm{~g} / \mathrm{L}$ glucose, $2 \mathrm{~g} / \mathrm{L}$ yeast extract, $6 \mathrm{~g} / \mathrm{L} \mathrm{Na} \mathrm{HPO}_{4}, 0.5 \mathrm{~g} / \mathrm{L} \mathrm{NaCl}, 1 \mathrm{~g} / \mathrm{L} \mathrm{NH}_{4} \mathrm{Cl}$, $3.5 \mathrm{~g} / \mathrm{L} \mathrm{KH}_{2} \mathrm{PO}_{4}, 246.5 \mathrm{mg} / \mathrm{L} \mathrm{MgSO}_{4} \cdot 7 \mathrm{H}_{2} \mathrm{O}, 14.7 \mathrm{mg} / \mathrm{L}$ $\mathrm{CaCl}_{2} \cdot 2 \mathrm{H}_{2} \mathrm{O}, 27.8 \mathrm{mg} / \mathrm{L} \mathrm{FeSO}_{4} \cdot 7 \mathrm{H}_{2} \mathrm{O}$, and $2 \mathrm{~g} / \mathrm{L}$ sodium citrate dihydrate. The fed-batch medium contained (per liter) $10 \mathrm{~g}$ of glucose, $8 \mathrm{~g}$ of $\left(\mathrm{NH}_{4}\right)_{2} \mathrm{HPO}_{4}, 13.3 \mathrm{~g}$ of $\mathrm{KH}_{2} \mathrm{PO}_{4}, 1.2 \mathrm{~g}$ of $\mathrm{MgSO}_{4} \cdot 7 \mathrm{H}_{2} \mathrm{O}, 1.7 \mathrm{~g}$ of citric acid, and $10 \mathrm{~mL}$ of a trace metal solution that contained (per liter of $5 \mathrm{M} \mathrm{HCl}) 10 \mathrm{~g}$ of $\mathrm{FeSO}_{4} \cdot 7 \mathrm{H}_{2} \mathrm{O}, 2.25 \mathrm{~g}$ of $\mathrm{ZnSO}_{4}$. $7 \mathrm{H}_{2} \mathrm{O}, 1 \mathrm{~g}$ of $\mathrm{CuSO}_{4} \cdot 5 \mathrm{H}_{2} \mathrm{O}, 0.5 \mathrm{~g}$ of $\mathrm{MnSO}_{4} \cdot 5 \mathrm{H}_{2} \mathrm{O}, 0.23 \mathrm{~g}$ of $\mathrm{Na}_{2} \mathrm{~B}_{4} \mathrm{O}_{7} \cdot 10 \mathrm{H}_{2} \mathrm{O}, 2 \mathrm{~g}$ of $\mathrm{CaCl}_{2} \cdot 2 \mathrm{H}_{2} \mathrm{O}$, and $0.1 \mathrm{~g}$ of $\left(\mathrm{NH}_{4}\right)_{6} \mathrm{MO}_{7} \mathrm{O}_{24}$. When necessary, the medium was supplemented with $50 \mathrm{ug} / \mathrm{mL}$ kanamycin, $100 \mathrm{ug} / \mathrm{mL}$ ampicillin, and $17 \mathrm{ug} / \mathrm{mL}$ chloramphenicol.

\section{DNA manipulation}

All plasmids used in this study are listed in Table 1 and all primers used in this study for PCR are listed in Additional file 1: Table S1. XcP4H (NCBI Reference Sequence: WP_011035413.1), TfP4H (NCBI Reference Sequence: WP_028838552.1), HeP4H (NCBI Reference Sequence: WP_013332010.1), phhB (GenBank: RMS51283.1), folM (GenBank: EFM2067767.1), SaPsmH (GenBank: AIA00687.1) and SaPsmF (NCBI Reference Sequence: WP_020929557.1) genes were cloned from the corresponding strains. SaP4H (W199F mutant) (NCBI Reference Sequence: WP_016572394.1), CtP4H (W239F mutant) (NCBI Reference Sequence: WP_012354318.1), SaCOMT (NCBI Reference Sequence: WP_016577150.1) and OsCOMT (NCBI Reference Sequence: XP_015650053.1) genes were all codon optimized and synthesized by Generay (Shanghai, China). All plasmids were assembled by Gibson assembly method using the ClonExpress MultiS One Step Cloning Kit (Vazyme, Nanjing China). The construction of plasmids was listed in Additional file 1. The replacement of the native promoter involved in the methionine cycle with the Anderson promoter No. J23108 (ctgacagctagctcagtcctaggtataatgctagc) and the deletion of the $d c m$ and spe $\mathrm{D}$ genes were performed by $\lambda$-red recombination. The target sequences were also assembled by the ClonExpress MultiS One Step Cloning Kit. To replace the promoters of the Mtn, luxS, $m e t F$, and $m e t K$ genes, PCR was performed to obtain the upstream region, the kan resistance gene containing FRT at both ends, the promoter and RBS and the beginning of the gene's ORF as the downstream region. Then, the PCR products described above were assembled to obtain the target genes. According to the $\lambda$-red recombination protocol, various E. coli BW25113AtnaA derivatives were constructed. Knockout of $\mathrm{dcm}$ and speD were performed in essentially the same manner as that described above. The target genes used for the deletion of the $\mathrm{dcm}$ and speD genes were made by ligating the upstream region, the kan resistance gene containing FRT at both ends and the downstream region in order.

\section{Production of melatonin in E. coli BW25113 tnaA}

The melatonin-producing strains were cultured in $100 \mathrm{~mL}$ LB media (500-mL shaking flask) at $37{ }^{\circ} \mathrm{C}$ and $200 \mathrm{rpm}$ until the $\mathrm{OD}_{600}$ reached 0.6. The enzymes were induced with $0.1 \% \mathrm{~L}$-arabinose. After incubation at $30{ }^{\circ} \mathrm{C}$ and $200 \mathrm{rpm}$ for $8 \mathrm{~h}, 200$ OD cells were harvested by centrifugation at $4{ }^{\circ} \mathrm{C}$ and $5000 \times g$ for $10 \mathrm{~min}$. This induced bacterial pellet was suspended into $20 \mathrm{~mL}$ M9Y media (50-mL flask) containing $2 \mathrm{~g} / \mathrm{L}$ tryptophan, $4 \mathrm{~g} / \mathrm{L}$ methionine (and 3\% glycerin when necessary) and grown at $30{ }^{\circ} \mathrm{C}$ and $200 \mathrm{rpm}$. Samples were collected at $3 \mathrm{~h}, 6 \mathrm{~h}$, $12 \mathrm{~h}, 24 \mathrm{~h}, 48 \mathrm{~h}, 72 \mathrm{~h}$, and $96 \mathrm{~h}$, and the concentrations of 5-HTP, NAS and melatonin were analyzed by HPLC. Acetyl Coenzyme A kit (Solarbio, Beijing, China) was used to detect the concentration of acetyl coenzyme A. Bioscreen C (Lab Systems Helsinki, Finland) was used to measure the grow curve of E. coli BW25113.

\section{Production of 5-HTP in E. coli BW25113}

E. coli BW25113 $\triangle$ tnaA was transformed with the pBAD-Sa5HTP, pBAD-Xc5HTP, pBAD-Tf5HTP, pBADHe5HTP and pBAD-Ct5HTP plasmids. The culture methods were the same as described above (production of melatonin), and 200 OD-induced cultures were harvested and suspended into $20 \mathrm{~mL}$ of M9Y medium containing $2 \mathrm{~g} / \mathrm{L}$ tryptophan and grown at $30{ }^{\circ} \mathrm{C}$ and $200 \mathrm{rpm}$. Samples were collected at the time points described above and analyzed by HPLC.

\section{Fed-batch fermentation and optimization}

A single colony of Ec-MEL8 from a cell plate was inoculated into $5 \mathrm{~mL} \mathrm{LB}$ media and cultured at $37{ }^{\circ} \mathrm{C}$ and $200 \mathrm{rpm}$ overnight. Then, $1 \%(\mathrm{v} / \mathrm{v})$ of the culture was transferred into $100 \mathrm{ml} \mathrm{LB}$ media (500-mL flask) and 
Table 1 Strains and plasmids used in the study

\begin{tabular}{|c|c|c|}
\hline Strains and plasmids & Relevant characteristics & Source \\
\hline \multicolumn{3}{|l|}{ Strains } \\
\hline E. coliTrans1-T1 & $\mathrm{F}-\varphi 80($ lacZ) $\Delta M 15 \Delta$ lacX74hsdR (rk-, mk+) $\Delta r e c A 1398$ endA1tonA & Transgene company \\
\hline E. coli BW25113 & 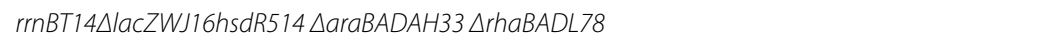 & Laboratory storage \\
\hline E. coli BW25113 $\Delta t n a A$ & wild type $\Delta$ tnaA & Laboratory storage \\
\hline ECSC5HTP & BW25113 $\triangle$ tnaA harboring pBAD-Sa5HTP & This work \\
\hline ECXC5HTP & BW25113 $\triangle$ tnaA harboring PBAD-XC5HTP & This work \\
\hline EcHe5HTP & BW25113 $\triangle$ tnaA harboring pBAD-He5HTP & This work \\
\hline EсTf5HTP & BW25113 $\triangle$ tnaA harboring pBAD-Tf5HTP & This work \\
\hline EcCt5HTP & BW25113 $\triangle$ tnaA harboring pBAD-Ct5HTP & This work \\
\hline EcSaCOMT & BW25113 $\triangle$ tnaA harboring pBAD-SaCOMT & This work \\
\hline EcOsCOMT & BW25113 $\triangle$ tnaA harboring pBAD-OsCOMT & This work \\
\hline ECMEL1 & BW25113 $\triangle$ thaA harboring pBAD-MEL1 & This work \\
\hline ECMEL2 & BW25113 $\triangle$ tnaA harboring pBAD-MEL2 & This work \\
\hline ECMEL3 & BW25113 $\triangle$ tnaA harboring pBAD-XC5HTP and pZS-MEL1 & This work \\
\hline ECMEL4 & BW25113 $\Delta$ tnaA harboring pBAD-Xc5HTP and pZS-MEL2 & This work \\
\hline ECHFSaCOMT & BW25113 $\Delta$ tnaA harboring pZS-MEL1 & \\
\hline EcHFOsCOMT & BW25113 $\Delta$ tnaA harboring PZS-MEL2 & \\
\hline ECMEL5 & BW25113 $\triangle$ tnaA harboring pBAD-5HTPCOMTsa and pZS-PsmHF & This work \\
\hline ECMEL6 & BW25113 $\triangle$ tnaA harboring pBAD-5HTPCOMTos and pZS-PsmHF & This work \\
\hline ECMEL7 & BW25113 $\Delta$ tnaA harboring pBAD-XcP4H-OsCOMT and pZS-SaPsmHF-phhBfolM & This work \\
\hline ECMEL7-1 & EcMEL7 + over expression of metk & This work \\
\hline ECMEL7-2 & ECMEL7 + over expression of $m t n$ & This work \\
\hline ECMEL7-3 & ECMEL7 + over expression of luxs & This work \\
\hline ECMEL7-4 & EcMEL7 + over expression of $m t n$ and luxs & This work \\
\hline ECMEL7-5 & ECMEL7\speD & This work \\
\hline ECMEL7-6 & EcMEL7 $\triangle d c m$ & This work \\
\hline ECMEL8 & BW25113 $\Delta$ tnaA $\triangle$ speD harboring pBAD-XCP4H-OsCOMT2 and pZS-SaPsmHF-phhBfolM & This work \\
\hline ECMELCXPM & BW25113 $\Delta$ tnaA $\Delta s p e D$ harboring pBAD-OsCOMT2-XcP4H-PhhB-FolM and pZS-SaPsmHF & This work \\
\hline ECMELCX & 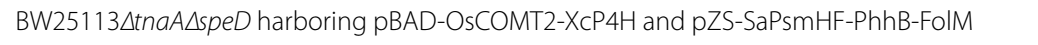 & This work \\
\hline ECMELCS & 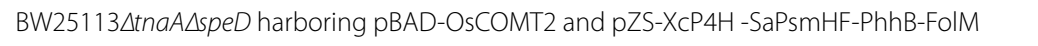 & This work \\
\hline ECMELC $_{T 7} \mathrm{~S}$ & $\begin{array}{l}\text { BW25113 } \Delta \text { tnaA } \Delta \text { speD (DE3) harboring pBAD-P } \mathrm{T}_{\mathrm{T}} \mathrm{OsCOMT2} \text { and pZS-XCP4H -SaPsmHF-PhhB- } \\
\text { FolM }\end{array}$ & This work \\
\hline ECMELC $_{\mathrm{tac}} \mathrm{S}$ & BW25113 $\Delta$ tnaA $\Delta$ speD harboring pBAD-PtacOsCOMT2 and pZS-XcP4H -SaPsmHF-PhhB-FolM & This work \\
\hline \multicolumn{3}{|c|}{ 然 } \\
\hline pKD46 & $\begin{array}{l}\text { AmpR, } \lambda \text {-Red recombinase expression plasmid, ara-inducible expression, temperature sensi- } \\
\text { tive replication }\end{array}$ & Laboratory storage \\
\hline pKD13 & Kan $^{R}$, oriR plasmid containing an FRT-aph-FRT cassette & Laboratory storage \\
\hline pCP20 & $A m p^{R}, \mathrm{Cm}^{R}$, repA(Ts), pSC101 based vector expressing the yeast Flp recombinase & Laboratory storage \\
\hline pBAD/HisA & Amp ${ }^{R}$, pBR322 origin, araBAD promoter, araC gene & Laboratory storage \\
\hline pZS & $\mathrm{Cm}^{\mathrm{R}}$, p15A origin, pBAD based vector expressing recombinase & Laboratory storage \\
\hline pBAD-Sa5HTP & pBAD containing SaP4H, phhB, FolM genes & This work \\
\hline pBAD-Xc5HTP & pBAD containing $\mathrm{XCP}_{\mathrm{C}} \mathrm{H}$, phhB, FolM genes & This work \\
\hline pBAD-He5HTP & pBAD containing $\mathrm{HeP} 4 \mathrm{H}$, phhB, FolM genes & This work \\
\hline pBAD-Tf5HTP & pBAD containing TfP4H, phhB, FolM genes & This work \\
\hline pBAD-Ct5HTP & pBAD containing $\mathrm{CtP} 4 \mathrm{H}$, phhB, FolM genes & This work \\
\hline pBAD-SaCOMT & pBAD containing SaCOMT & This work \\
\hline pBAD-OsCOMT & pBAD containing OsCOMT & This work \\
\hline pBAD-MEL1 & pBAD containing SaP4H, phhB, FolM, SaPsmH, SaPsmF, SaCOMT & This work \\
\hline pBAD-MEL2 & pBAD containing SaP4H, phhB, FolM, SaPsmH, SaPsmF, OsCOMT & This work \\
\hline pZS-MEL1 & pZS containing SaPsmH, SaPsmF, SaCOMT & This work \\
\hline
\end{tabular}


Table 1 (continued)

\begin{tabular}{|c|c|c|}
\hline Strains and plasmids & Relevant characteristics & Source \\
\hline pZS-MEL2 & pZS containing SaPsmH, SaPsmF, OsCOMT & This work \\
\hline pBAD-5HTPCOMTsa & pBAD containing SaP4H, phhB, FolM, SaCOMT & This work \\
\hline pBAD-5HTPCOMTos & pBAD containing SaP4H, phhB, FolM, OsCOMT & This work \\
\hline pZS-PsmHF & pZS containing SaPsmH, SaPsmF & This work \\
\hline pBAD-XcP4H-OsCOMT & pBAD containing $\mathrm{SaP} 4 \mathrm{H}, \mathrm{OsCOMT}$ & This work \\
\hline pBAD-XcP4H-OsCOMT2 & pBAD containing SaP4H, OsCOMT (C303F, V321T) & This work \\
\hline pZS-SaPsmHF-phhBfolM & pZS containing SaPsmH, SaPsmF, phhB, FolM & This work \\
\hline pBADOsCOMT2-XcP4H-PhhB-FolM & pBAD containing OsCOMT2, XcP4H, PhhB, FolM & This work \\
\hline pBADOsCOMT2-XcP4H & pBAD containing OsCOMT2, XcP4H & This work \\
\hline pBAD-XcP4H-OsCOMT2 & pBAD containing $\mathrm{XcP}_{\mathrm{C}} \mathrm{H}$, OsCOMT2 & This work \\
\hline pBAD-OsCOMT2 & pBAD containing OsCOMT2 & This work \\
\hline $\mathrm{pBAD}-\mathrm{P}_{\mathrm{T}} \mathrm{OsCOMT2}$ & pBAD containing $\mathrm{P}_{\mathrm{T} 7}$-OsCOMT2 & This work \\
\hline pBAD-P $\mathrm{tac}_{\mathrm{tac}} \mathrm{OsCOMT2}$ & pBAD containing $\mathrm{P}_{\mathrm{tac}}-\mathrm{OsCOMT2}$ & This work \\
\hline
\end{tabular}

grown at $37{ }^{\circ} \mathrm{C}$ and $200 \mathrm{rpm}$ for approximately $8-10 \mathrm{~h}$. $5 \%(\mathrm{v} / \mathrm{v})$ of the cultures were transferred to a 2-L bioreactor (BXBIO, Shanghai, China) with $1 \mathrm{~L}$ fed-batch media. The $\mathrm{pH}$ was controlled at 6.8 by automatic feeding of $30 \%$ (v/v) $\mathrm{NH}_{4} \mathrm{OH}$, and the temperature was set at $37{ }^{\circ} \mathrm{C}$. The dissolved oxygen concentration was maintained above $20 \%$ air saturation by supplying air at $1 \mathrm{vvm}$ (air volume/ working volume/minute) and by automatically controlling the agitation speed up to $700 \mathrm{rpm}$. When the initial $10 \mathrm{~g} / \mathrm{L}$ glucose was consumed, a feeding solution containing $500 \mathrm{~g}$ of glucose and $10 \mathrm{~g}$ of $\mathrm{MgSO}_{4} \cdot 7 \mathrm{H}_{2} \mathrm{O}$ per liter was periodically added. When the $\mathrm{OD}_{600}$ reached 20 , the culture was induced by adding L-arabinose to a final concentration of $1 \mathrm{~g} / \mathrm{L}$, the temperature was set at $30^{\circ} \mathrm{C}$, and a solution of $4 \mathrm{~g} / \mathrm{L}$ tryptophan, $6 \mathrm{~g} / \mathrm{L}$ methionine and 3\% $(\mathrm{v} / \mathrm{v})$ glycerol was added to the media. Samples were collected to measure the biomass concentrations $\left(\mathrm{OD}_{600}\right)$ and glucose concentrations (SBA-40E biosensor analyzer (Institute of Biology, Shandong Province Academy of Sciences, China)) and for HPLC analysis. For optimized conditions, the culture was induced when $\mathrm{OD}_{600}$ reached 40 and after $12 \mathrm{~h}$ induction, a solution of $6 \mathrm{~g} / \mathrm{L}$ tryptophan, $10 \mathrm{~g} / \mathrm{L}$ methionine and 3\% (v/v) glycerol was added to the media.

\section{HPLC analysis and LC/MS}

L-tryptophan from Sigma (St. Louis., USA), 5-HTP from Aladdin (Shanghai, China), NAS from Sigma and melatonin from Aladdin (Shanghai, China) were used as the standards. The standards and the supernatant concentration of tryptophan, 5-HTP and NAS were measured after dilution of the samples with methanol/water $(15: 85 \mathrm{v} / \mathrm{v})$. For analysis of melatonin, standard and supernatant of cultures were diluted to a final concentration of methanol/water $(40: 60 \mathrm{v} / \mathrm{v})$. The samples were filtered through a $0.22-\mu \mathrm{m}$ nylon filter and then analyzed by HPLC (Agilent 1260 series, Hewlett-Packard) using an Agilent ZORBAX Eclipse Plus C18 column $(4.6 \times 100 \mathrm{~mm}$, 3.5-Micron). Tryptophan, 5-HTP and NAS were quantified under $275 \mathrm{~nm}$ UV detection with methanol/water $(15: 85 \mathrm{v} / \mathrm{v})$ as the mobile phase. Melatonin was quantified under $290 \mathrm{~nm}$ UV detection with methanol/water (40:60 $\mathrm{v} / \mathrm{v}$ ) as the mobile phase. NAS and melatonin were identified by QTRAP 6500 and AB SCIEX using Gemini $3 \mu \mathrm{m}$ NX-C18 $110 \AA(50 \times 2 \mathrm{~mm})$ with 95\% methanol (containing $0.1 \%$ formic acid) and $5 \%$ water (containing $0.1 \%$ formic acid) (v/v).

\section{Results and discussion}

Conceptual design of the melatonin biosynthetic pathway by virtue of the physostigmine pathway

When searching tryptophan derivatives in prokaryotes, we found three intermediates of physostigmine biosynthesis (5-HTP, 5-HT, and NAS) in Streptomyces albulus are shared by melatonin biosynthesis. Enlightened by the physostigmine biosynthetic pathway, a novel biosynthetic pathway for melatonin production was designed (Fig. 1). In the first catalytic step of physostigmine biosynthesis, the production of 5-HTP was proposed to be catalyzed by TPH. However, the gene encoding TPH was not included in the physostigmine biosynthesis gene cluster and was not specifically identified in the report. In animals, TPH and phenylalanine 4-hydroxylase $(\mathrm{P} 4 \mathrm{H})$ are two subgroups of aromatic amino acid hydroxylases (AAAHs) that share high sequence similarity. BLASTP analysis of the TPH homolog in the S. albulus genome revealed a putative $\mathrm{AAAH}$, which has typical characteristics of $\mathrm{P} 4 \mathrm{H}(\mathrm{SaP} 4 \mathrm{H})$. It was reported that some bacterial $\mathrm{P} 4 \mathrm{Hs}$ exhibit activity towards both phenylalanine and tryptophan. Moreover, the substitution of a small 


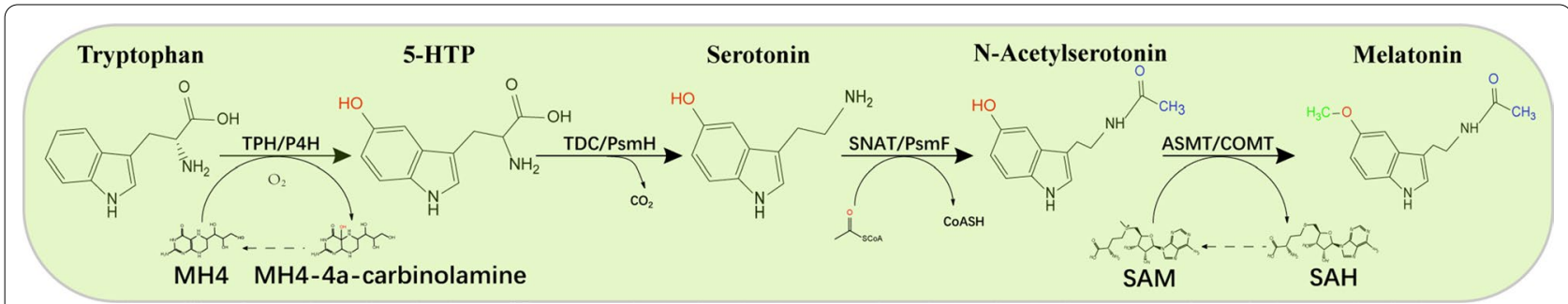

Fig. 1 The melatonin biosynthesis pathway. TPH, tryptophan hydroxylase; 5-HTP, 5-Hydroxytryptophan; TDC, tryptophan decarboxylase; SNAT, serotonin $\mathrm{N}$-acetyltransferase; ASMT, N-acetylserotonin methyltransferase; COMT, caffeic acid O-methyltransferase; SAM, S-adenosylmethionine; SAH, S-adenosylhomocysteine

number of residues (e.g., W179F substitution) causes the preferred substrate of $\mathrm{P} 4 \mathrm{H}$ to change from phenylalanine to tryptophan [22]. Therefore, SaP4H was used to establish the 5-HTP biosynthetic pathway. Alternative P4Hs from other bacteria, including Xanthomonas campestris [22], Halomonas elongata, Thermomonas fusca, and Cupriavidus taiwanensis [27], were also selected to catalyze the first step of melatonin biosynthesis. The genes encoding homologs of PsmH and PsmF were selected from S. albulus to establish the second and third catalytic steps of melatonin biosynthesis. For the final step of melatonin biosynthesis, two kinds of enzymes: ASMT and COMT have been identified to exhibit the catalytic activity. ASMT, as a methyltransferase initially identified in animals and plants, had low enzyme activities, indicating its role as a rate-limiting enzyme in melatonin synthesis [28]. Besides, ASMT was noncompetitively inhibited by NAS and melatonin and competitively inhibited by its product S-adenosylhomocysteine (SAH) [29, 30]. Compared with ASMT, COMT, which is a methyltransferase found in plants [31], also O-methylates NAS to melatonin with a much higher catalytic capacity (100 times) than that of ASMT [20, 32]. Therefore, COMT from Oryza sativa (OsCOMT) was the preferred enzyme, and this enzyme exhibits the highest activity for converting NAS to melatonin as ever reported [12]. In S. albulus, BLASTP analysis revealed a putative gene encoding COMT, which shared the highest sequence identity with OsCOMT. The resulting SaCOMT and OsCOMT were then selected to establish the final catalytic step of melatonin biosynthesis.

Above all, we designed a new melatonin biosynthetic pathway in E. coli based on the physostigmine biosynthetic pathway. All four proteins from S. albulus, namely, $\mathrm{SaP} 4 \mathrm{H}, \mathrm{SaCOMT}, \mathrm{SaPsmF}$ and SaPsmH, were expressed well as soluble recombinant proteins in E. coli. Among these genes, the genes encoding $\mathrm{SaP} 4 \mathrm{H}$ and SaCOMT were optimized according to the E. coli codon preference, while the genes encoding SaPsmF and SaPsmH were not optimized. The 5-HTP biosynthetic module and COMT were involved in the first and final steps of melatonin biosynthesis. According to previous reports, these two steps were proposed to be the rate-limiting of melatonin production and were tested first $[9,20]$.

\section{Engineering the biosynthetic module to produce 5HTP in E. coli}

The 5-HTP biosynthetic module was engineered in three ways (Fig. 2a). First, the W179F substitution was discovered to change the preferred substrate of $\mathrm{P} 4 \mathrm{H}$ from phenylalanine to tryptophan and hence to enhance its TPH activity. Thus, the W179F substitution was introduced into various $\mathrm{P} 4 \mathrm{Hs}$ (Fig. 2b), and the resulting genes encoding the $\mathrm{W} 179 \mathrm{~F}$ mutant were cloned into the pBAD vector under the control of the arabinose-inducible araBAD promoter. Second, a tetrahydromonapterin (MH4) recycling system was constructed to provide cofactor to P4Hs. The genes encoding PhhB from P. aeruginosa and FolM from E. coli were cloned and inserted downstream of the genes encoding the W179F mutants of P4Hs in the pBAD plasmid (Fig. 2a). The resulting plasmids were named pBAD-Sa5HTP, pBAD-Xc5HTP, pBAD-Tf5HTP, pBAD-He5HTP and pBAD-Ct5HTP. Third, the E. coli mutant strain (abbreviated Ec $\Delta t n a A$ ), in which the tnaA gene encoding tryptophanase was deleted to block the degradation of tryptophan and 5-HTP, was generated (Fig. 2a). The pBAD-5HTP plasmids were transformed into the Ec $\Delta$ tnaA strain, and all the recombinant proteins were well expressed (Additional file 1: Fig. S1a). The whole-cell biocatalysis of tryptophan to 5-HTP in these strains at different intervals was analyzed and compared. As shown in Fig. 2c, all the strains could produce 5-HTP after the addition of tryptophan, confirming the successful establishment of the 5-HTP biosynthesis module. However, the strain harboring the putative $\mathrm{SaP} 4 \mathrm{H}$ from S. albulus displayed the lowest level of 5-HTP production. It seemed that the putative $\mathrm{P} 4 \mathrm{H}$ W199F of S. albulus might exhibit lower catalytic activity toward tryptophan. It is also possible that other unknown tryptophan hydroxylases were involved in the conversion 

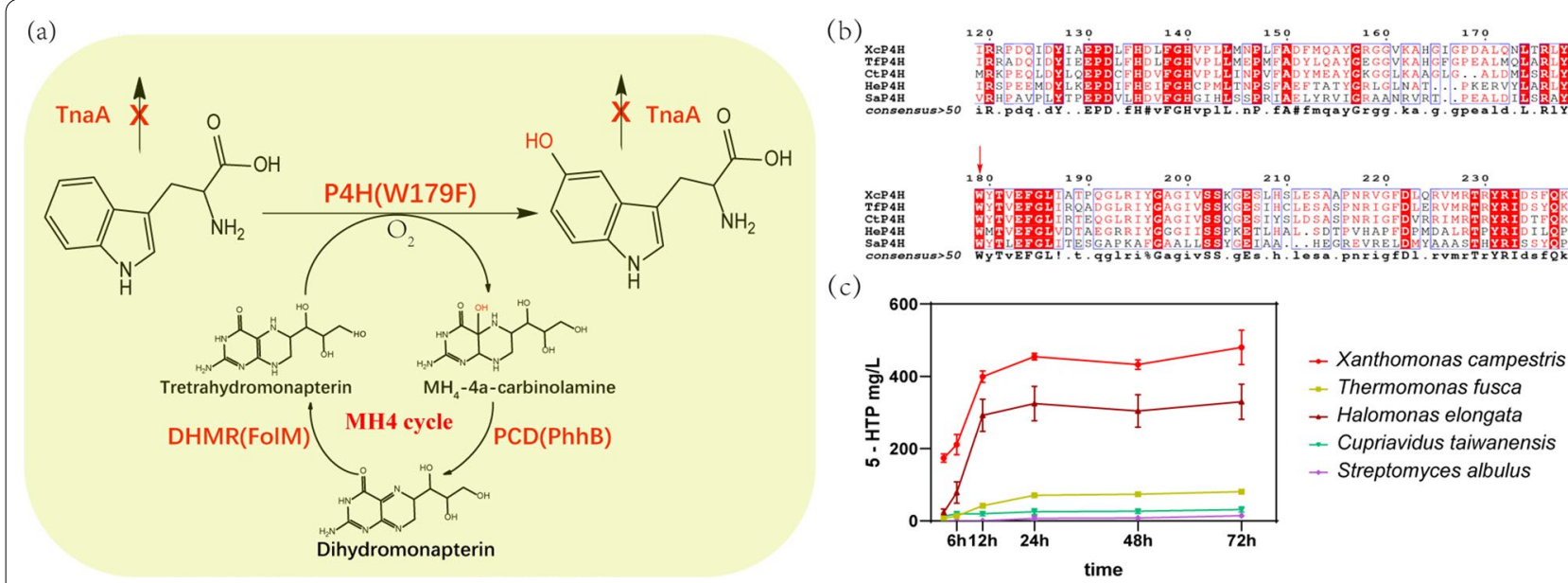

Fig. 2 Prokaryotic P4Hs catalyzed the formation of 5-HTP in E. coli. a The biosynthetic pathway of 5-HTP constructed in E. coliAtnaA. b Partial results of $\mathrm{P} 4 \mathrm{H}$ alignment. The sequences and functional domains of $\mathrm{P} 4 \mathrm{Hs}$ were highly conserved, and the arrows indicate the site requiring the mutation of tryptophan to phenylalanine. $\mathbf{c}$ Effect of P4H on 5-HTP production in recombinant Escherichia coli. 5-HTP levels were subjected to HPLC, and the data are the means \pm standard deviations of triplicate experiments

of tryptophan to 5-HTP during physostigmine biosynthesis. The XcP4H-W179F exhibited superior catalytic activity toward tryptophan (Fig. 2c), which is in accordance with a previous report. It produced $\sim 500 \mathrm{mg} / \mathrm{L} 5$-HTP in the shake flask with tryptophan supplied. Thus, XcP4HW179F was used as the 5-HTP biosynthetic module in subsequent pathway engineering.

\section{COMT overexpression enabled melatonin production from NAS}

Two genes encoding COMT from $S$. albulus and $O$. sativa were singly cloned into the $\mathrm{PBAD}$ vector under the control of the araBAD promoter. The resulting $\mathrm{pBAD}$ SaCOMT and $\mathrm{pBAD}-\mathrm{OsCOMT}$ plasmids were transformed into the strain Ec $\Delta t n a A$, resulting in EcSaCOMT and EcOsCOMT, respectively, and the soluble proteins were obtained (Additional file 1: Fig. S1b). By adding NAS and methionine, the capabilities of the two COMTs in the biocatalysis of NAS to melatonin were tested. As shown in Fig. 3, both COMTs facilitated the conversion of NAS to melatonin, suggesting that both COMTs could be used in engineering a pathway for melatonin production. The strain harboring OsCOMT produced significantly higher levels of melatonin than the strain harboring SaCOMT, and SDS-PAGE analysis showed that the expression of OsCOMT was much higher than that of SaCOMT. Two COMT genes were coupled with other intermediate product synthesis genes to be constructed on the coexpression plasmid to verify their ability to increase the production of melatonin. As far as we know, this was the first reported COMT protein identified in microorganisms, which has expanded the COMT candidate gene

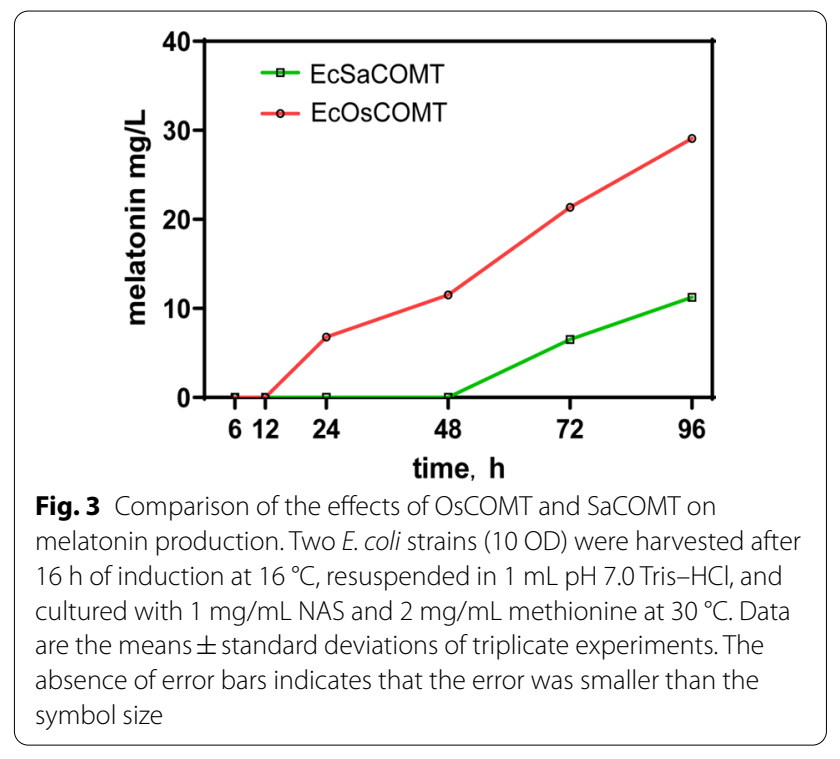

pool involved in melatonin biosynthesis. Combined with $\mathrm{SaP} 4 \mathrm{H}, \mathrm{SaPsmH}$ and SaPsmF, a putative pathway of melatonin synthesis in S. albulus was identified.

\section{Melatonin production pathway engineering}

Based on the 5-HTP biosynthetic module and the COMT from $S$. albulus or O. sativa, a complete melatonin production pathway was constructed (Additional file 1: Fig. S2). With all the genes responsible for melatonin biosynthesis expressed from a single pBAD plasmid in the Ec $\triangle$ tnaA strain, the recombinant strains EcMEL1 and EcMEL2 (with either SaCOMT or OsCOMT) were 
assembled. Besides, another two strains, namely EcMEL3 and EcMEL4, were made by placing the genes encoding $\mathrm{SaPsmH}, \mathrm{SaPsmF}$ and COMT on another plasmid (pZS), with the 5-HTP biosynthetic module on the pBAD plasmid. Unexpectedly, melatonin was not produced in all these four strains, while significant NAS accumulation was observed (Fig. 4a). Results of SDS-PAGE (Additional file 1: Fig. S3) showed that the proteins necessary for the synthesis of melatonin were well expressed, except for the last enzyme, COMT, which catalyzed NAS to melatonin. These results indicated that the weak or absent expression of COMT might restricted the production of melatonin. To improve the expression of COMT in the recombinant strains, a series of plasmid modifications were carried out (Additional file 1: Fig S2C-G). When we moved COMT from pZS plasmid to pBAD plasmid, a clear OsCOMT band was observed and a total of $12.29 \pm 0.13 \mathrm{mg} / \mathrm{L}$ melatonin was produced by Ec-MEL6 in flasks, while no obvious melatonin or SaCOMT was produced by EcMEL5 (Fig. 4a, Additional file 1: Fig S4a). Thus, OsCOMT is more superior for the bioconversion of NAS to melatonin than SaCOMT in this system.
Whereas the synthesis of melatonin was still blocked at the step catalyzed by COMT. During the whole-cell biocatalytic, the production of NAS in EcMEL6 was nearly $200 \mathrm{mg} / \mathrm{L}$, which was about 15 -fold of melatonin. This indicated that COMT expression is of vital importance for melatonin production.

In order to enhance the expression of OsCOMT and achieved higher melatonin yields, the next melatoninproducing strain, EcMEL7, was made by placing the gene encoding OsCOMT immediately downstream of the $\mathrm{XcP} 4 \mathrm{H}$. Results showed that the production of melatonin by the EcMEL7 strain was increased to $18.64 \pm 0.46 \mathrm{mg} / \mathrm{L}$ (Fig. 4a). SDS-PAGE analysis confirmed that the expression of OsCOMT was enhanced in the EcMEL7 cells (Additional file 1: Fig S4b). To further increase the expression of OsCOMT, we also shifted OsCOMT to the front of $\mathrm{XP} 4 \mathrm{H}$ or put OsCOMT singly on the pBAD plasmid (Additional file 1: Fig S2J). However, when OsCOMT was shifted to the upstream of $\mathrm{XP} 4 \mathrm{H}$, the recombinant strains did not show an increased in COMT expression but had a significantly decreased soluble expression of $\mathrm{XP} 4 \mathrm{H}$ (Additional file 1: Figure S4c), which caused the

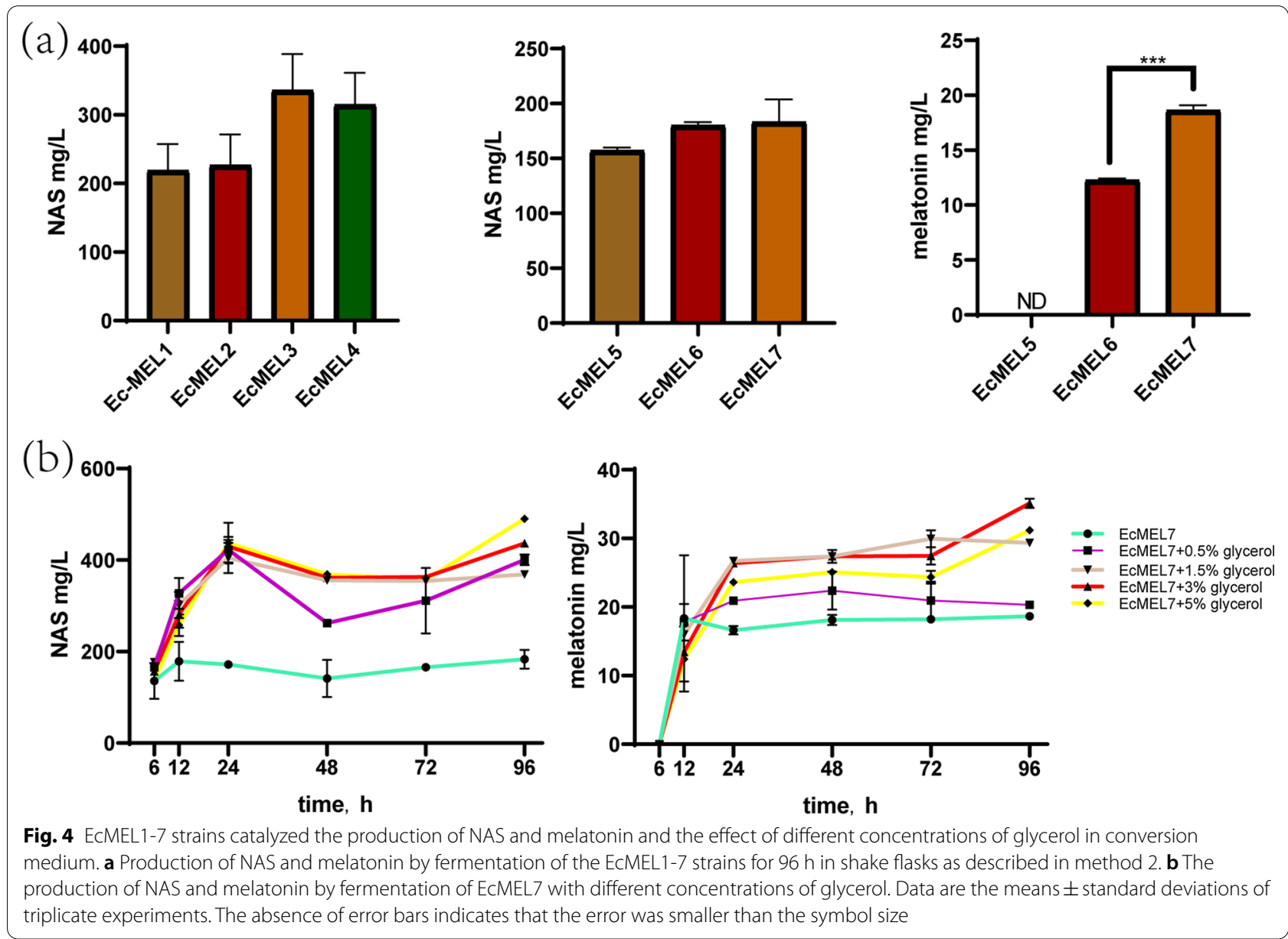


synthesis of melatonin blocked in the first step. When putting OsCOMT on the pBAD plasmid alone, and even replacing Para with a stronger promoter such as $\mathrm{P}_{\mathrm{T} 7}$ or $\mathrm{P}_{\mathrm{tac}}$, the expression of COMT and the production of melatonin were not increased compared to that of EcMEL7 (Additional file 1: Figure S5a, b). It seemed that the expression of COMT has reached its limit in the current six enzymes co-expression system. Even when the gene elements involved in the COMT expression were enhanced, a stronger expression would not be achieved due to the limitation of resources related to transcription and translation.

\section{Improved production of melatonin by Cofactor engineering and protein engineering}

After the establishment of the complete melatonin biosynthetic pathway, cofactor engineering and protein engineering were conducted to further enhance melatonin production. First, cofactor engineering was conducted to increase the supply of acetyl-CoA and SAM, resulting in a significant increase in melatonin production. AcetylCoA is an important cofactor of PsmF that is involved in the biosynthesis of NAS from 5-HT. HPLC analysis of the supernatant of EcMEL7 showed a large amount of 5-HT accumulation (data not show). The low conversion efficiency of 5-HT to NAS might indicate the lack of acetylCoA. Glucose, acetate and glycerol were reported to be able to provide energy and the acetyl group for acetyltransferase in E. coli $[33,34] .10 \mathrm{~g} / \mathrm{L}$ glucose, $50 \mathrm{mM}$ acetate or $5 \%$ glycerol was added to M9 medium and the whole-cell biocatalytic efficiency of EcMEL7 was evaluated. Results showed that glycerol effectively increased the yield of NAS compared with that of glucose and acetate (Additional file 1: Fig. S6). As shown in Additional file 1: Fig S7, the level of Acetyl Coenzyme A in the supernatant was increased by $55 \%$ after adding glycerol, which confirmed that glycerol augmented the PsmF activity by facilitating the availability of Acetyl Coenzyme A cofactor. Therefore, different concentrations of glycerol were tested in the whole-cell bioconversion of melatonin from tryptophan. The highest production of NAS was $569.82 \pm 16.88 \mathrm{mg} / \mathrm{L}$ in the shake flask (Fig. 4b). Moreover, the addition of glycerol also significantly increased the production of melatonin (Fig. 4b). The increase in the production of melatonin was glycerol concentrationdependent. The highest level of melatonin was achieved: $35.13 \pm 0.66 \mathrm{mg} / \mathrm{L}$ (Fig. $4 \mathrm{~b}$ ) when $3 \%$ glycerol was added into the whole-cell catalysis system. Thus, subsequent optimization experiments all added 3\% glycerol.

Radical $S$-adenosylmethionine (SAM), the other important cofactor, plays a key role in the process of COMT catalysis. SAM is a common methyl donor in vivo that participates in the rate-limiting steps of the biosynthesis of multiple compounds and undergoes many genome modifications to remove inhibition [35]. Research on the enzyme activity of COMT in plants showed that it was positively correlated with the SAM/SAH ratio [35-37]. To test whether increased SAM levels and decreased SAH accumulation could improve the potential of COMT and hence enhance the production of melatonin in E. coli, a series of genes related to SAM recycling were deleted or overexpressed (Fig. 5a). Among the deleted and overexpressed genes, deletion of the speD gene increased the production of melatonin by two-fold (Fig. 5c). The SpeD catalyzed decarboxylation of SAM to produce dSAM: one of the precursors involving spermidine synthesis. Deletion of speD gene reduced the consumption of SAM and provided more methyl donors to enhance melatonin synthesis. In addition, speD knockout has no significant effect on the growth of BW25113 $\Delta$ tnaA (Additional file 1: Fig S8). The modification of $m t n$, luxS, and $d c m$ increased the production of NAS, but does not caused significant differences $(\mathrm{p}>0.05)$ in melatonin production (Fig. 5c).

Wang et al. reported that amino acid substitutions near the NAS-binding pocket (C296F, Q310L, and V314T) significantly enhanced the catalytic activity of COMT from Arabidopsis thaliana (AtCOMT) [38]. The corresponding residues of $\mathrm{C} 296$ and V314 are conserved in OsCOMT, while Q310 is not (Fig. 5b). Thus, the corresponding substitutions of C296F and V314T were introduced to OsCOMT, yielding OsCOMT2. OsCOMT2 increased melatonin production to $122.83 \pm 4.44 \mathrm{mg} / \mathrm{L}$, which was fivefold higher than the melatonin production with OsCOMT (Fig. 5c). By combining the mutation of OsCOMT and the deletion of speD, the EcMEL8 strain was obtained. EcMEL8 produced $136.17 \pm 1.33 \mathrm{mg} / \mathrm{L}$ melatonin and $879 \pm 71.42 \mathrm{mg} / \mathrm{L}$ NAS in a shake flask (Fig. 5c). Figure $5 \mathrm{~d}$ showed the HPLC analysis of the EcMEL8 fermentation supernatant, and the target products were confirmed by LC-MS (Fig. 5e). The results showed that almost all the consumed tryptophan $(4.94 \mathrm{mM})$ was converted into NAS and melatonin $(4.12 \mathrm{mM}+0.56 \mathrm{mM})$, and other tryptophan derivatives were negligible. As reported by Luo et al., the engineered strain produced high levels of byproduct AcTRPM when achieved high yields of melatonin in the fed-batch fermentation process with tryptophan as substrate, due to the TRPM-forming activity of the TDC (tryptophan decarboxylase) [21]. However, the PsmH and PsmF proteins from the physostigmine pathway were very specific to their substrates [23], and the EcMEL8 strain did not produce obvious byproducts. Compared to the EcMEL7 strain, the yield of melatonin produced by EcMEL8 was effectively improved and the ratio of NAS/melatonin 
(a)

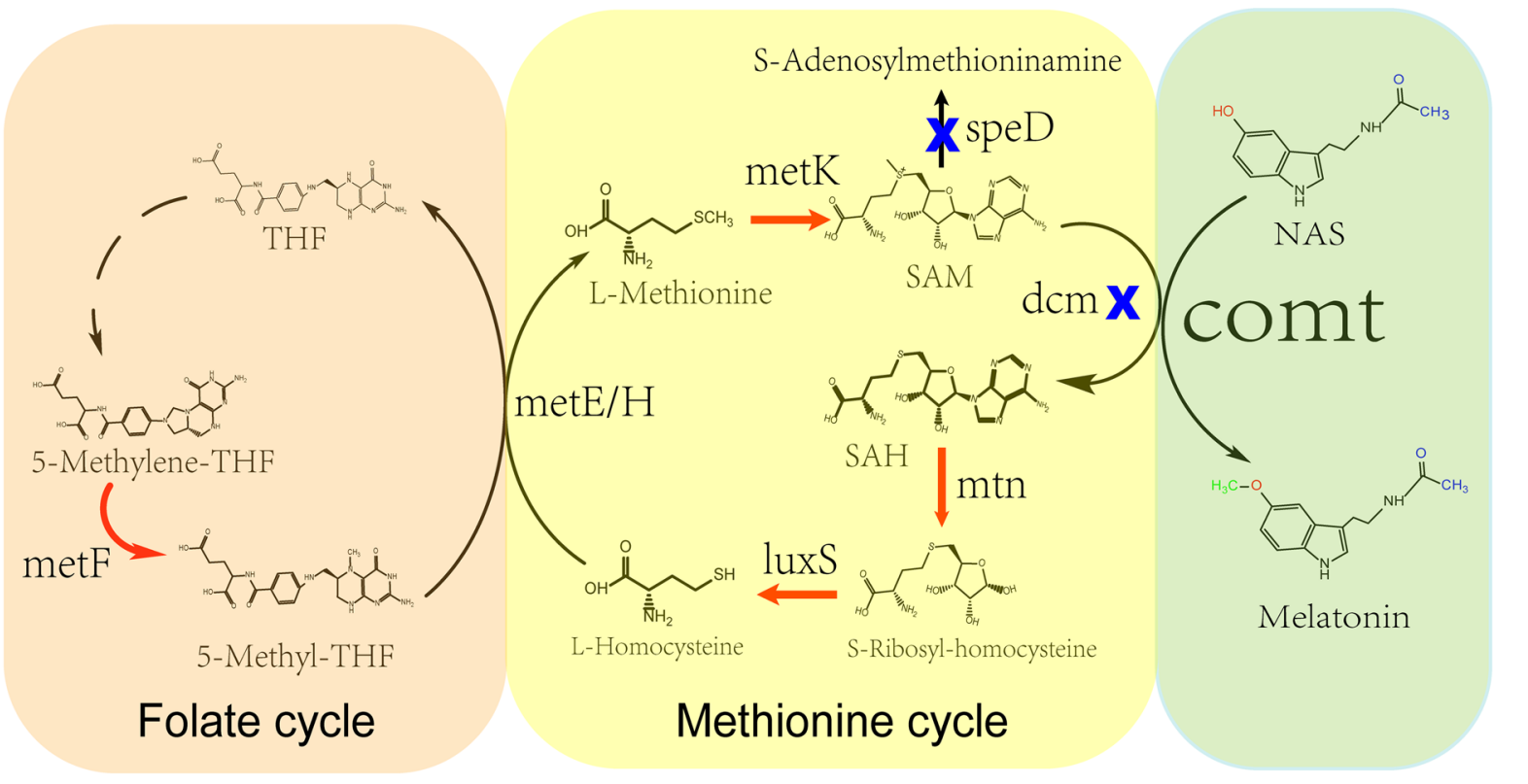

(b)

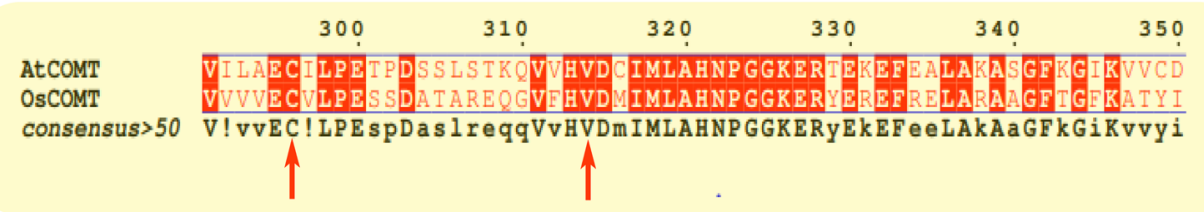

(c)

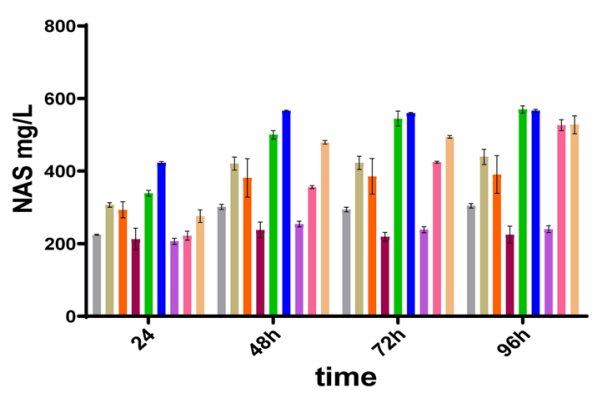

(d)

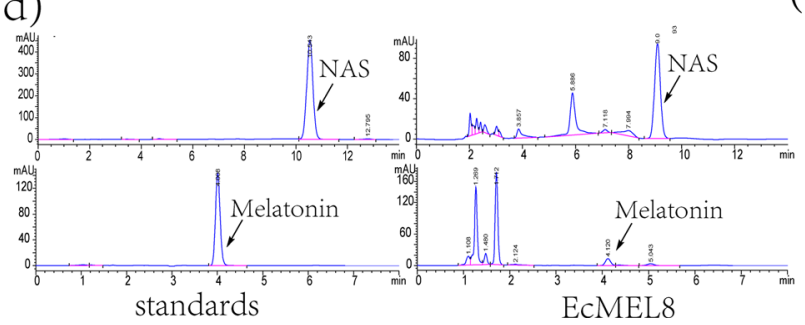

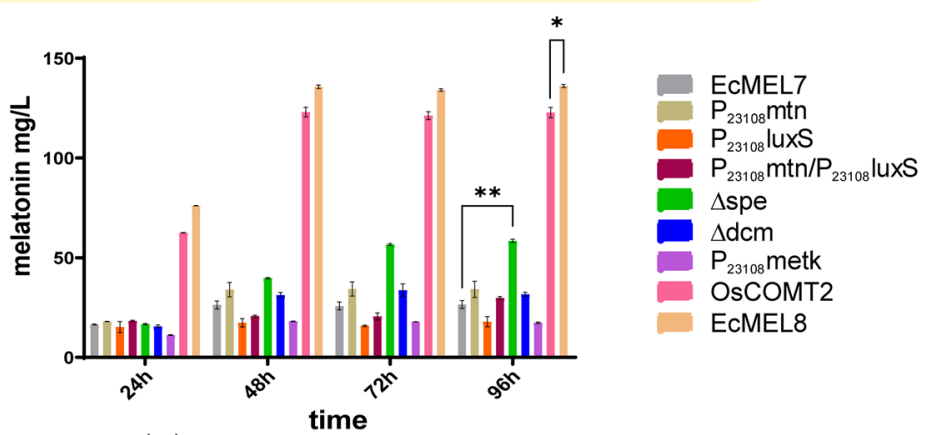

(e)
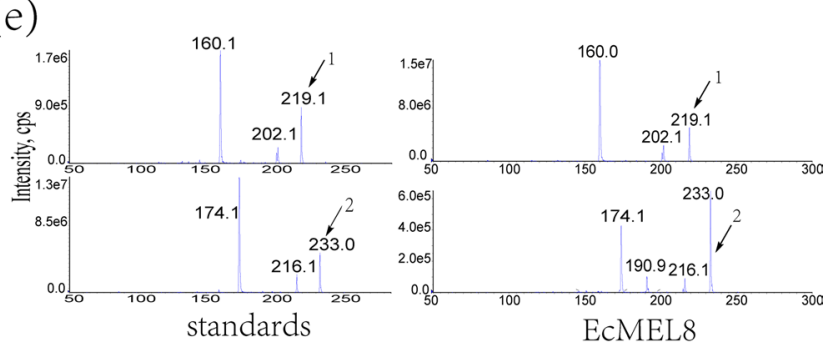

Fig. 5 Cofactor engineering and protein engineering for high-level production of melatonin. a Metabolic engineering for cofactor SAM of COMT. The red arrow indicates the enhanced expression of the gene, and the blue cross indicates the knockout of the gene. $\mathbf{b}$ Alignment of the OsCOMT and AtCOMT protein sequences. c Conversion of tryptophan to NAS and melatonin by recombinant E. coli strains. $\mathbf{d} \mathrm{HPLC}$ analysis of the standard and bioconversion products of the representative ECMEL8 strain. e LC-ESI-MS analysis of symbols from panel d: exact mass of compound $1[\mathrm{M}+\mathrm{H}]^{+}[\mathrm{m} / \mathrm{z}](219.1)$, compound $2[\mathrm{M}+\mathrm{H}]^{+}[\mathrm{m} / \mathrm{z}](233.0)$. Data are the means \pm standard deviations of triplicate experiments 

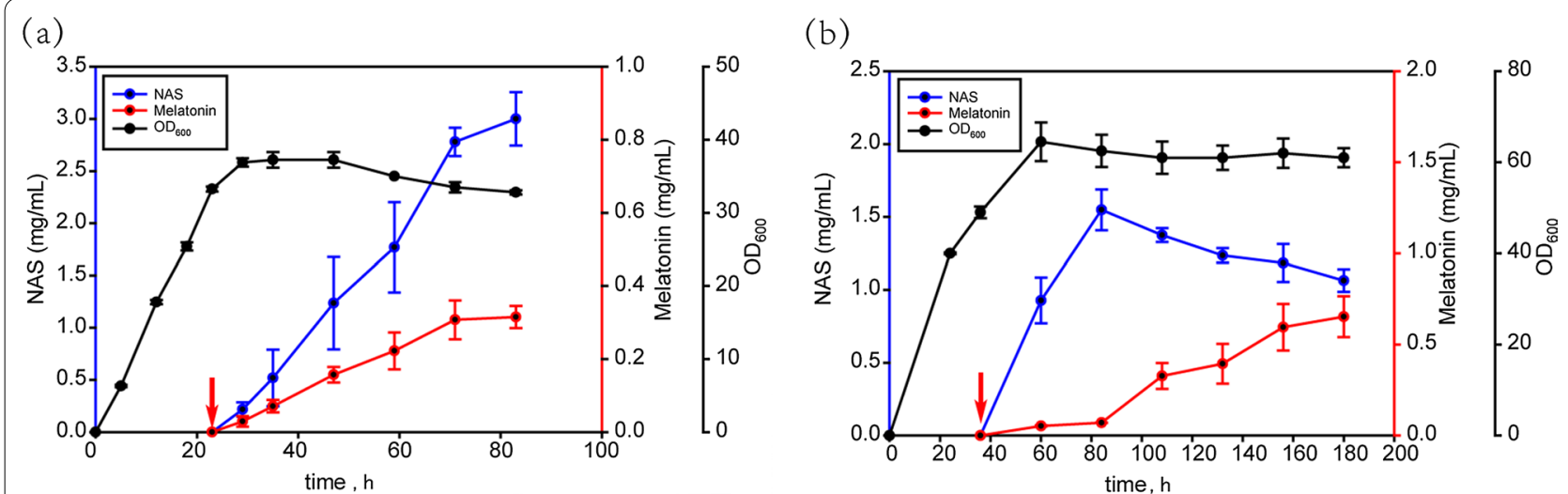

Fig. 6 High-level melatonin production in a fermenter. a Fed-batch fermentation of EcMEL8. The cultures were added $0.1 \% \mathrm{~L}$-arabinose at $18 \mathrm{~h}$. The red arrow indicates the time ( $23 \mathrm{~h}$ ) at which tryptophan, methionine, and $3 \%$ glycerol were added to the fermenter. The NAS and melatonin concentrations were measured at 29 h, 35 h, 47 h, 59 h, 71 h, and 83 h. b Fed-batch fermentation of EcMEL 8 after optimization. Those were induced at $24 \mathrm{~h}$ with $0.1 \% \mathrm{~L}$-arabinose. Tryptophan, methionine, and $3 \%$ glycerol were added to the fermenter at $36 \mathrm{~h}$. The NAS and melatonin concentrations were measured at $60 \mathrm{~h}, 84 \mathrm{~h}, 108 \mathrm{~h}, 132 \mathrm{~h}, 156 \mathrm{~h}$, and $180 \mathrm{~h} .(\mathrm{n}=2)$

production was reduced, suggested that the bioconversion of NAS to melatonin was successfully enhanced. Nevertheless, the fivefold higher level of NAS than melatonin in EcMET8 indicated that COMT was still the rate-limiting step for the production of melatonin in this study.

\section{High-level melatonin production in a fermenter}

Whole-cell bioconversion of tryptophan to melatonin in EcMET8 was also performed in a 2-L fermenter with a higher cell density $\left(\mathrm{OD}_{600}=38\right)$. Melatonin yield reached its highest level in the medium of $0.32 \pm 0.03 \mathrm{~g} / \mathrm{L}$ at $71 \mathrm{~h}$ with the synthesis efficiency of melatonin produced via per g of dry cell weight (DCW) at $35 \mathrm{mg} / \mathrm{g}$ DCW. NAS production continued to increase even after $83 \mathrm{~h}$ and reached $3.0 \pm 0.26 \mathrm{~g} / \mathrm{L}$ (Fig. 6a). Thus, both melatonin and NAS production were significantly higher in this system than in shake flasks. The cell transformation efficiency was reduced compared with that of the shake flask. This may be due to the limitations of the fermentation process. After the optimization of fermentation conditions, Fig. $6 \mathrm{~b}$ showed that the accumulation of NAS decreased to $1.06 \pm 0.07 \mathrm{~g} / \mathrm{L}$, and the melatonin production finally reached $0.65 \pm 0.11 \mathrm{~g} / \mathrm{L}$ at $180 \mathrm{~h}$. The higher $\mathrm{OD}$ value, as expected, brought a higher production of melatonin. Under the optimized fermentation conditions, the melatonin synthesis efficiency of EcMEL8 reached $59 \mathrm{mg} / \mathrm{g}$ DCW, which was even higher than the strain reported by Luo et al. However, the limitation of the final step of melatonin synthesis in EcMEL8 was not completely eliminated: high levels of NAS accumulated in the fermenter. Subsequent further work should focus on removing the problem of NAS accumulation to improve melatonin production.

\section{Conclusions}

In this study, the melatonin synthesis pathway in Streptomyces albicans was identified, and a new melatonin biosynthesis pathway in Escherichia coli was successfully constructed on this basis. By balancing heterologous proteins expression elements, optimizing cofactors supplementation, and modifying the rate-limiting enzyme COMT, the production of melatonin was increased by 11 -fold. In this study, the gene resource library of the melatonin synthesis pathway was extended to prokaryotic genes, which provided a fast and excellent synthesis pathway for the production of tryptophan derivatives in genetically engineered strains.

\section{Supplementary Information}

The online version contains supplementary material available at https://doi. org/10.1186/s12934-021-01662-8.

\footnotetext{
Additional file 1. Supplementary Fig. 1. (a), SDS-PAGE analysis of pBAD5HTPs. The red arrow indicates the expression of P4Hs. (b), SDS-PAGE analysis of EcSaCOMT and EcOsCOMT. Supplementary Fig. 2. Construction of plasmids for expression of melatonin-related proteins. Supplementary Fig 3. SDS-PAGE analysis of ECMEL1, ECMEL2, ECMEL3, and ECMEL4. Supplementary Fig 4. SDS-PAGE analysis of ECMEL5, ECMEL6, ECMEL7, ECMELCX and ECMELCXPM. Supplementary Fig. 5. Comparison of the melatonin production by ECMEL7, ECMELCS, ECMEL-CtacS and ECMEL-CT7S. Supplementary Fig 6. Comparison of adding glucose, acetate and glycerol in M9Y medium for biosynthesis of NAS and melatonin. Supplementary Fig. 7. The concentration of Acetyl Coenzyme A in ECMEL7 and ECMEL7+5\% glycerol during the whole-cell biocatalysis. Supplementary Fig. 8 . The grow curve of BW25113 $\Delta$ tnaA and BW25113 $\Delta$ tnaA $\triangle$ speD. Table S1. Primers used in DNA manipulation. Table $\mathrm{S} 2$. The $\mathrm{OD}_{600}$ of Melatonin Producing Strains in M9Y medium. Table S3. The $\mathrm{OD}_{600}$ of Melatonin Producing Strains after adding glucose, glycerol, and acetate.
} 


\section{Acknowledgements}

We are grateful to Ying Fu at Public Technology Service Center, Institute of Microbiology, Chinese Academy of Sciences for her technical support in LC-MS/MS data collection.

\section{Authors' contributions}

YFZ and SZ conceived the project and designed the experiments. YFZ, YZH, NZ and JJG performed the experiments. SZ, YFZ and YZH analyzed the data and wrote the manuscript. ZYD provided resources and revised the manuscript. All authors read and approved the final manuscript.

\section{Funding}

This research was supported by the National Key R\&D Program of China (2018YFC0310703), the program of China Ocean Mineral Resources R\&D Association (DY135-B2-02), and National Natural Science Foundation of China (Grant No. 31770103).

\section{Declarations}

\section{Ethics approval and consent to participate} Not applicable.

\section{Consent for publication}

Not applicable.

\section{Competing interests}

This work has been included in patent applications by the Institute of Microbiology, Chinese Academy of Sciences.

\section{Author details}

${ }^{1}$ State Key Laboratory of Microbial Resources, Institute of Microbiology, Chinese Academy of Sciences, No. 1 West Beichen Road, Chaoyang District, Beijing 100101, People's Republic of China. ${ }^{2}$ University of Chinese Academy of Sciences, Beijing 100049, People's Republic of China. ${ }^{3}$ Shenzhen Siyomicro Bio-Tech C., LTD, No. 39 Qingfeng Avenue, Baolong Community, Longgang District, Shenzhen 518116, People's Republic of China.

Received: 1 February 2021 Accepted: 18 August 2021

Published online: 28 August 2021

\section{References}

1. Manchester LC, Coto-Montes A, Boga JA, Andersen LP, Zhou Z, Galano A, Vriend J, Tan DX, Reiter RJ. Melatonin: an ancient molecule that makes oxygen metabolically tolerable. J Pineal Res. 2015;59:403-19.

2. Pandi-Perumal SR, Srinivasan V, Maestroni GJ, Cardinali DP, Poeggeler B, Hardeland R. Melatonin: nature's most versatile biological signal? FEBS J. 2006;273:2813-38.

3. Zhao D, Yu Y, Shen Y, Liu Q, Zhao Z, Sharma R, Reiter RJ. Melatonin synthesis and function: evolutionary history in animals and plants. Front Endocrinol (Lausanne). 2019;10:249.

4. Reiter RJ, Tan D-X, Fuentes-Broto L. Melatonin: a multitasking molecule. In: Neuroendocrinology: the normal neuroendocrine system; 2010, pp 127-51 (Progress in Brain Research).

5. Cipolla-Neto J, Amaral FGD. Melatonin as a hormone: new physiological and clinical insights. Endocr Rev. 2018;39:990-1028.

6. Arnao MB, Hernandez-Ruiz J. Functions of melatonin in plants: a review. J Pineal Res. 2015;59:133-50.

7. Altun A, Ugur-Altun B. Melatonin: therapeutic and clinical utilization. Int J Clin Pract. 2007:61:835-45.

8. Juhnevica-Radenkova K, Moreno DA, Ikase L, Drudze I, Radenkovs V. Naturally occurring melatonin: sources and possible ways of its biosynthesis. Compr Rev Food Sci Food Saf. 2020;19:4008-30.

9. Sun T, Chen L, Zhang W. Microbial production of mammalian melatonin-a promising solution to melatonin industry. Biotechnol J. 2016;11:601-2.

10. Khater MM, Issa YM, Shoukry AF. Effect of substituents on the ionization-constants of some 8-quinolinol azo-compounds. J Prakt Chem. 1980;322:470-4.
11. Axelrod J. The pineal gland: a neurochemical transducer. Science. 1974; $184: 1341-8$

12. Back K, Tan DX, Reiter RJ. Melatonin biosynthesis in plants: multiple pathways catalyze tryptophan to melatonin in the cytoplasm or chloroplasts. J Pineal Res. 2016;61:426-37.

13. De Luca V, Marineau C, Brisson N. Molecular cloning and analysis of cDNA encoding a plant tryptophan decarboxylase: comparison with animal dopa decarboxylases. Proc Natl Acad Sci U S A. 1989;86:2582-6.

14. Noe W, Mollenschott C, Berlin J. Tryptophan decarboxylase from Catharanthus roseus cell suspension cultures: purification, molecular and kinetic data of the homogenous protein. Plant Mol Biol. 1984;3:281-8.

15. Fujiwara T, Maisonneuve S, Isshiki M, Mizutani M, Chen L, Wong HL, Kawasaki T, Shimamoto K. Sekiguchi lesion gene encodes a cytochrome P450 monooxygenase that catalyzes conversion of tryptamine to serotonin in rice. J Biol Chem. 2010;285:11308-13.

16. Byeon Y, Lee HY, Lee K, Back K. Caffeic acid O-methyltransferase is involved in the synthesis of melatonin by methylating $\mathrm{N}$-acetylserotonin in Arabidopsis. J Pineal Res. 2014;57:219-27.

17. Tan DX, Hardeland R, Back K, Manchester LC, Alatorre-Jimenez MA, Reiter RJ. On the significance of an alternate pathway of melatonin synthesis via 5-methoxytryptamine: comparisons across species. J Pineal Res. 2016;61:27-40

18. Luo H, He C, Han L. Heterologous expression of ZjOMT from Zoysia japonica in Escherichia coli confers aluminum resistance through melatonin production. PLOS ONE. 2018;13:e0196952.

19. Germann SM, Baallal Jacobsen SA, Schneider K, Harrison SJ, Jensen NB, Chen X, Stahlhut SG, Borodina I, Luo H, Zhu J, et al. Glucose-based microbial production of the hormone melatonin in yeast Saccharomyces cerevisiae. Biotechnol J. 2016;11:717-24.

20. Byeon Y, Back K. Melatonin production in Escherichia coli by dual expression of serotonin $\mathrm{N}$-acetyltransferase and caffeic acid O-methyltransferase. Appl Microbiol Biotechnol. 2016;100:6683-91.

21. Luo H, Schneider K, Christensen U, Lei Y, Herrgard M, Palsson BO. Microbial synthesis of human-hormone melatonin at gram scales. ACS Synth Biol. 2020;9:1240-5.

22. Lin $Y$, Sun $X$, Yuan $Q$, Yan $Y$. Engineering bacterial phenylalanine 4-hydroxylase for microbial synthesis of human neurotransmitter precursor 5-hydroxytryptophan. ACS Synth Biol. 2014;3:497-505.

23. Liu J, Ng T, Rui Z, Ad O, Zhang W. Unusual acetylation-dependent reaction cascade in the biosynthesis of the pyrroloindole drug physostigmine. Angew Chem Int Ed Engl. 2014;53:136-9.

24. Zhang J, Marcin C, Shifflet MA, Salmon P, Brix T, Greasham R, Buckland B, Chartrain M. Development of a defined medium fermentation process for physostigmine production by Streptomyces griseofuscus. Appl Microbiol Biotechnol. 1996;44:568-75.

25. Chartrain M, Katz L, Taylor C, Zhang J, Brix T, Salmon P, Greasham R. Physostigmine production by Streptomyces griseofuscus NRRL 5324: process development and scale-up studies. J Ind Microbiol . 1995;15:414-7.

26. Datsenko K, Wanner B. One-step inactivation of chromosomal genes in Escherichia coli K-12 using PCR products. Proc Natl Acad Sci U S A. 2000;97:6640-5.

27. Mora-Villalobos JA, Zeng AP. Synthetic pathways and processes for effective production of 5-hydroxytryptophan and serotonin from glucose in Escherichia coli. J Biol Eng. 2018;12:3.

28. Botros HG, Legrand $\mathrm{P}$, Pagan C, Bondet $\mathrm{V}$, Weber $\mathrm{P}$, Ben-Abdallah $\mathrm{M}$, Lemiere N, Huguet G, Bellalou J, Maronde E, et al. Crystal structure and functional mapping of human ASMT, the last enzyme of the melatonin synthesis pathway. J Pineal Res. 2013;54:46-57.

29. Morton DJ, Kock N. Some properties of pineal gland hydroxyindole0-methyltransferase from black rhinoceros (Diceros bicornis). J Pineal Res. 1990;8:35-40.

30. Tedesco SC, Morton OJ, Reiter RJ. Hydroxyindole-0-methyltransferase activity in the pineal gland of the muskox (Ovibos moschatus). J Pineal Res. 1994;16:121-6.

31. Koshiba T, Hirose N, Mukai M, Yamamura M, Hattori T, Suzuki S, Sakamoto M, Umezawa T. Characterization of 5-hydroxyconiferaldehyde O-methyltransferase in Oryza sativa. Plant Biotechnol. 2013;30:157-67.

32. Byeon $\mathrm{Y}$, Choi GH, Lee HY, Back K. Melatonin biosynthesis requires $\mathrm{N}$-acetylserotonin methyltransferase activity of caffeic acid O-methyltransferase in rice. J Exp Bot. 2015;66:6917-25. 
33. He YZ, Gong J, Yu HY, Tao Y, Zhang S, Dong ZY. High production of ectoine from aspartate and glycerol by use of whole-cell biocatalysis in recombinant Escherichia coli. Microb Cell Fact. 2015;14:55.

34. Zhang S, Yang W, Chen H, Liu B, Lin B, Tao Y. Metabolic engineering for efficient supply of acetyl-CoA from different carbon sources in Escherichia coli. Microb Cell Fact. 2019;18:130.

35. Moffatta BA, Weretilnykb EA. Sustaining S-adenosyl-L-methioninedependent methyltransferase activity in plant cells. Physiol Plant. 2001;113:435-42.

36. Wu Z, Ren H, Xiong W, Roje S, Liu Y, Su K, Fu C. Methylenetetrahydrofolate reductase modulates methyl metabolism and lignin monomer methylation in maize. J Exp Bot. 2018;69:3963-73.
37. Kunjapur AM, Hyun JC, Prather KL. Deregulation of S-adenosylmethionine biosynthesis and regeneration improves methylation in the E. coli de novo vanillin biosynthesis pathway. Microb Cell Fact. 2016;15:61.

38. Wang W, Su S, Wang S, Ye L, Yu H. Significantly improved catalytic efficiency of caffeic acid $\mathrm{O}$-methyltransferase towards $\mathrm{N}$-acetylserotonin by strengthening its interactions with the unnatural substrate's terminal structure. Enzyme Microb Technol. 2019;125:1-5.

\section{Publisher's Note}

Springer Nature remains neutral with regard to jurisdictional claims in published maps and institutional affiliations.
Ready to submit your research? Choose BMC and benefit from:

- fast, convenient online submission

- thorough peer review by experienced researchers in your field

- rapid publication on acceptance

- support for research data, including large and complex data types

- gold Open Access which fosters wider collaboration and increased citations

- maximum visibility for your research: over $100 \mathrm{M}$ website views per year

At BMC, research is always in progress.

Learn more biomedcentral.com/submissions 